\title{
On the Demonisation and Fetishisation of Choice in Christian Sexual Ethics
}

\author{
Christopher Craig Brittain, University of Aberdeen \\ To be published in the journal Studies in Christian Ethics 27.2 (2014): 144-166 \\ For the definitive final text version, please go to: \\ DOI: $\underline{10.1177 / 0953946813514008}$
}

\begin{abstract}
:
This essay analyses attitudes towards freedom of choice in theological reflections on sexuality. It explores common contradictions that often emerge in such accounts, including: the reaffirmation of disavowed simplicity, the affirmation of biological determinism at the expense of interpersonal values, and a distrust of choice, which effectively amounts to a choice not to choose. It shows that while conservative Christian sexual ethicists often demonise individual freedom of choice, liberal theology often fetishises such freedom. These tensions are contrasted with alternative approaches to sexuality, in the form of Rowan Williams' concept of the 'body's grace', and Kathleen Roberts Skerrett's notion of 'incarnating the other'. The discussion argues that contributions of each of these theologians require greater analysis of the contemporary social and cultural forces shaping contemporary sexual practices. The essay explores this entwinement between sexuality and the ideal of freedom in contemporary culture, through a discussion of Jonathan Franzen's novel Freedom.
\end{abstract}

KEYWORDS: Choice, Jonathan Franzen, Freedom, Stanley Hauerwas, Marc Jordan, Gilbert Meilaender, Sexual Ethics, Kathleen Skerrett, Rowan Williams

'All things are lawful for me, but not all things beneficial' (1Cor 6: 12)

Many contemporary theologians lament that Christian sexual ethics is in serious disarray. Mainline Christian denominations are tearing themselves apart over disagreements about homosexuality; the media publishes a steady stream of accounts of sexual abuse committed by clergy; meanwhile, few young church members, let alone most citizens in wider society, appear to take seriously church teachings on sex. Sarah Coakley has attributed the failure of the churches to address issues surrounding sexuality to three cultural contradictions regarding sexual desire. The first is a pervasive pessimism that assumes that celibacy is impossible. Coakley notes, however, that such an assertion undermines that equally insistent cultural belief that some forms of sexual desire must not be enacted (incest, sex with minors, bestiality, etc). The second contradiction is the predominance of feuds over the question of homosexual marriage among mainline churches, at the same time that 
heterosexual marriage is in crisis (rising divorce rates, exponential growth in single-parent families, etc). The third contradictory assumption Coakley observes is that celibacy and marriage are generally understood to be opposites, ignoring the reality that many marriages undergo periods of 'celibate' behaviour for a variety of reasons (ill health, physical separation, impotence, etc). ${ }^{1}$

These perceptive observations shed some light on difficulties relating to the articulation of a mature theological ethic of sexuality in the current cultural climate. Yet these three contradictions do not directly address some of the Church's own difficulties in dealing with sex. Moreover, the recognition of such contradictions raises the question of how these tensions are rooted in the nature of contemporary social arrangements. This essay explores the significance of this issue for Christian sexual ethics, while identifying additional contradictions inherent to the Church's own theological reflections on sexuality. These include: i) advocating a simplistic sexual ethics after initially acknowledging the complexity of sexuality; ii) reducing sexual ethics to biological determinism at the expense of interpersonal values; iii) choosing to argue that choice should not be permitted in sexual ethics; iv) a liberal fetishising of freedom without sufficiently attending to ways in which social context shapes one's choices. Each of these will be illustrated in turn.

Many of the theologians highlighted in this analysis advocate 'traditional' or 'conservative' positions. What they share collectively is a criticism of the influence of modernity and liberalism on sexual practice, challenging in particular any privileging of values such as freedom and choice in sexual ethics. While such a rejection is opposed in this essay, at the same time, the discussion acknowledges that these 'traditional' critics often articulate a deeper sensitivity to the social forces shaping the expressions of contemporary sexuality than those 'liberal' theologians who celebrate the values of freedom and choice. The discussion in the first section of this paper illustrates that while many conservative Christian ethicists have a tendency to demonise the freedom of choice, many liberals fetishise it.

Following this analysis, the essay engages with two promising theological accounts of sexuality - those of Rowan Williams and Kathleen Roberts Skerrett - who offer perspectives more attentive to the complexity of contemporary sexual ethics. The discussion argues that each author helps to enhance the primary theological proposal of the other, although each

\footnotetext{
${ }^{1}$ Sarah Coakley, 'Rethinking the sex crises in Catholicism and Anglicanism (part 1)', ABC Religion and Ethics (14 July 2010) http://www.abc.net.au/religion/articles/2010/07/14/2953473.htm [accessed 26 August 2012]
} 
does not fully address the cultural contradictions shaping contemporary sexuality. Some steps in that direction are developed by turning to Jonathan Franzen's novel Freedom, in the form of a theological discussion of its portrayal of the tensions between freedom and sexuality. Observing the oscillating nature of desire within the narrative's main characters illuminates that, rather than describing sexual relations as a sacramental means of grace (Williams) or analogically in terms of incarnation (Skerrett), the more aspirational nature of prayer serves as a more suitable comparison. Such a view reveals how the most appropriate doctrinal location for the Christian sexual ethics is eschatology rather than ecclesiology or the doctrine of creation. To help demonstrate why this is so, the essay turns first to examples of alternative views.

\section{Contradictions in Theological Accounts of Sexuality}

In the face of rising divorce and abortion rates, the proliferation of pornography in popular culture, and the questions of same-sex relationships and of trans-gendered identities, a number of Christian theologians blame the modern cultural ideal of freedom of choice, and such related values as individual self-fulfilment and self-determination, for the failures of Christian ethics. For a critic like Stanley Hauerwas, for example, the individualistic ideals of Enlightenment liberalism undermine Christian moral values and practices like humility and self-sacrifice. In opposition to the dominant cultural ethos in the West, therefore, he insists that 'Christians do not seek to be free but rather to be of use'. ${ }^{2}$ The result of such a perspective with regard to Christian sexual ethics is generally a restriction of sexual relationships to the confines of heterosexual marriage. As stated, such a response to the challenges of contemporary sexual ethics, however, often contains a number of problematic tensions and contractions, which undermine its coherence, not to mention their adoption by the majority of the population. Three such contradictions are illustrated in what follows, as well as a fourth contradictory tendency commonly found among liberal ethicists.

\subsection{Avoiding the dangers of freedom by reaffirming disavowed simplicity}

One persistent pattern within contemporary Christian theology is an approach that begins with an admission that an adequate ethics of sex is impossible in the face of the complexity of human sexuality. This is subsequently followed, however, by a straightforward reiteration of the view that sex can only be affirmed within the context of heterosexual

\footnotetext{
${ }^{2}$ Stanley Hauerwas, After Christendom (Nashville: Abingdon Press, 1991), 54.
} 
marriage. Stanley Hauerwas, for example, begins his essay 'Sex in Public' with a tone of seeming modesty: 'candor compels me to say that I cannot provide anything like an adequate ethic to deal with sex.... Christian ethicists are unsure what to say or how to respond to our culture's changing sexual mores. ${ }^{3}$ Just two pages later, however, he affirms as self-evident that Christian sexual ethics takes its form within the boundaries of heterosexual marriage (with no mention of the fact that the modern form and values of the 'institution of marriage' are relatively recent cultural conventions). ${ }^{4}$ This dramatic shift leaves the reader with the sense that the initial acknowledgement of the complexity of sexuality was rather disingenuous.

Dennis P. Hollinger initially avoids this contradiction. At the outset of The Meaning of Sex, he restricts Christian sex to vaginal insemination within marriage. The book concludes, however, with a chapter that can only be described as a lament over the 'highly sexualised nature of contemporary culture', which he acknowledges the Church has 'failed miserably' to counter. ${ }^{5}$ In other words, Hollinger acknowledges the complexity of sexuality at the end of his discussion, rather than at the beginning. Yet this admission does not lead to an analysis of the causes of the failure of the churches, anymore than it results in a careful diagnosis of how it is that western culture has become, as he phrases it, 'sex-crazed'. As such, Hollinger's engagement with the problem falls short both pastorally and theologically. At the practical level, the analysis does not diagnose any particular dynamics influencing contemporary attitudes towards sex. Theologically, the argument flirts with Pelagian works righteousness, for although he observes that 'the Church has failed miserably', it is simply told that it must work to become 'the embodiment of the meaning of sex' ${ }^{6}$ One might suggest that the Church's act of confession and self-examination need go further than this demand to suddenly embody moral purity in the face of what he himself calls an internal crisis.

Oliver O'Donovan's A Conversation Waiting to Begin intends to be a more probing and reflective contribution to contemporary sexual ethics. Indeed, O’Donovan recognises that

\footnotetext{
${ }^{3}$ Stanley Hauerwas, 'Sex in Public', The Hauerwas Reader, ed. John Berkman \& Michael Cartwright (Durham: Duke University Press, 2001), 481.

${ }^{4}$ Prior to the modern period, for example, marriage was generally viewed to be more about inheritance than emotional feelings, and the notion of mutual free choice or marrying for love were often not part of the arrangement. See: Jack Goody, The European Family (Oxford: Blackwell, 1999); Stephanie Coontz, Marriage a History: How Love Conquered Marriage (New York: Viking, 2005).

${ }^{5}$ Dennis P. Hollinger, The Meaning of Sex: Christian Ethics and the Moral Life. (Grand Rapids, MI: Baker Academic, 2009), 231.

${ }^{6}$ Ibid., 241.
} 
the traditional arguments over sexuality, along with the hermeneutical issues surrounding the biblical passages relating to homosexuality, have been repeatedly rehearsed without leading to resolution. Moreover, he accepts as a given the presence of homosexual (he does not specifically mention bi- or transsexual) Christians within the ecclesia. It is with such a constituency, he suggests, that a conversation has yet to begin, for he argues that the status and identity of homosexuals in the Church has thus far only been framed through the lens of concepts like 'justice' or 'liberation'. According to O'Donovan, until now, what he calls the 'Liberal Paradigm' has been speaking for gay Christians. He intends his volume to be a call for gay Christians to articulate for themselves their own understanding of their Christian experiences and vocation, in a manner which sets the dialogue 'within the basic terms set by the Christian faith. ${ }^{7}$

This is the point at which the contradictory pattern often found in Christian sexual ethics emerges. After having self-consciously (and charitably) defended the need for an open and hospitable conversation over homosexuality, O'Donovan seemingly dismisses out of hand the many LGBT Christian organizations that have been existent for decades, along with all theological writing published to date by LGBT theologians. ${ }^{8}$ The implication is that those gay Christians who have spoken to date have not been sufficiently theologically articulate to qualify as dialogue partners. The open invitation to conversation offered with one hand is withdrawn by the other when O'Donovan sets the boundaries of what will be recognised as a legitimate contribution prior to his debate even beginning. He would have his readers believe that, until now, LGBT people have not been speaking for themselves; rather, they have been seduced and manipulated by the 'Liberal paradigm'. This is not to say that one ought not to criticise the theological positions of LGBT individuals, but only that it is disingenuous to imply that such individuals have yet to speak theologically. Once again, a Christian ethicist makes a gesture towards recognizing the complexity of sexuality, only to reassert that the situation is actually rather simple.

\footnotetext{
${ }^{7}$ Oliver O'Donovan, A Conversation Waiting to Begin: The Churches and the Gay Controversy (London: SCM Press, 2009), 110.

${ }^{8}$ A brief sample of such organizations and writings will suffice to illustrate that LGBT Christians have been far from silent. Beyond the witness of individual LGBT Christians, organizations like Integrity, Changing Attitude, Evangelical Fellowship for Lesbian and Gay Christians, PFLAG, and Gay Christian Network have sought to articulate a Christian understanding of LGBT sexualities. Some theological texts include: Marcella AlthausReid, Indecent Theology (New York: Routledge, 2000); James Alison. Faith Beyond Resentment: Fragments Catholic and Gay (London: Darton, Longman \& Todd, 2001); Carter Heyward, Touching Our Strength (San Francisco: Harper, 1991); David Berger, Der heilige Schein: Als schwuler Theologe in der katholischen Kirche (Berlin: Ullstein Buchverlage, 2010).
} 


\subsection{Affirming biological or contextual determinism at the expense of interpersonal relations}

Another common pattern in Christian ethical discussions of sexuality is a defence of an ethic that restricts sex to vaginal insemination within the confines of marriage, which is founded on the biological distinction between male and female. The contradiction comes in two forms: first, methodologically, in the sense that a theological position is grounded by an appeal to biological givens; second, in the sense that the appeal to empirical biology displaces the moral relevance of personal motivations and relationships. An example of the first issue is found in the work of Dennis Hollinger, who seeks to ground his ethical approach to sex on both revealed morality and natural theology without clarifying how the 'givens' of scientific findings on sexuality relate to the 'givens' of scripture.'

For the second problem, Gilbert Meilaender's position in The Limits of Love is a case in point. In a chapter on marriage, he criticises the 'liberal' ethics of sexuality typified by James Nelson. Meilaender argues that, as Nelson seeks to challenge a perceived dualism between body and spirit in Christian understandings of the self, the latter neglects to distinguish between duality and dualism. ${ }^{10}$ The result, according to Meilaender, is that Nelson's concepts of 'mutuality' and 'embodiment' remain terribly vague. The same is true, he continues, of Nelson's criticism of sexist dualism between men and women. The solution to the problem of the sexism, Meilaender argues, is not an appeal to vague notions of 'communion in love' in order to overcome gender difference, but is found by affirming the value of the duality of the sexes while rejecting dualism: 'Those joined in a bond of mutual love are those who are different - other - and whose individuality is not obliterated or merged into undifferentiated oneness. ${ }^{11}$ The implication for any consideration of homosexuality is clear: 'Homosexual acts are forbidden precisely because lover and beloved are, biologically, not sufficiently other.' ${ }^{12}$

Meilaender's discussion does helpfully illustrate how vague sentimental concepts like 'mutuality' and 'communion' can be when given the task of bearing in themselves the weight of an ethic of sexuality. Relevant here, however, is the basis upon which Meilaender constructs his account: the particularities of measurable biological difference. But following this logic consistently leads to impliction that ethical sexual relations ought not simply to be

\footnotetext{
${ }^{9}$ Hollinger, The Meaning of Sex, 82.

${ }^{10}$ Gilbert Meilaender, The Limits of Love: Some Theological Explorations (University Park, PA: The Pennsylvania State University Press, 1987), chapter 10.

${ }^{11}$ Ibid., 119.

12 Ibid., 129.
} 
restricted to those possessing different genitalia, but also different cultural and socioeconomic backgrounds. Why not also specify linguistic difference? The less the couple resembles each other, the less likely they are to fall prey to what Meilaender considers to be the great sin of sexual relationship: when 'the relationship approaches too closely the forbidden love of self' ${ }^{13}$ According to Meilaender, the danger that sexual relationships might be reduced to narcissism can be avoided by ensuring that empirical biological difference is brought into the equation. That heterosexual relationships do not guarantee such an escape from narcissism will be discussed below; the more fundamental issue to note here is the way in which biology and empirical difference become the ground of moral theology.

Stanley Hauerwas develops an argument similar to that of Meilaender, but rather than root his position in biological difference, instead he emphasises the context of the church as the determinant of moral sexual ethics. For example, while challenging Nena and George O'Neill's defence of the concept of an 'open marriage', Hauerwas argues that they establish the depth of one's commitment to one's partner as the primary determinant in sexual relationships. Such an ethic suggests that what is permitted and what is forbidden 'should be determined by what we feel as individual human beings, not by some predetermined set of restrictive codes'. ${ }^{14}$ Hauerwas argues that this emphasis on trust and freedom encourages a certain kind of character: 'the ideal candidate for an open marriage turns out to be the selfinterested individual presupposed and encouraged by our liberal political structure and our capitalist consumer economy. ${ }^{15}$ This insight into the fact that the dynamics of capitalism shape cultural attitudes towards sexuality is an important one that will be returned to below. Here it is instructive to explore the antidote Hauerwas prescribes for the problem he diagnoses.

According to Hauerwas, the way to interrupt the reduction of sexual relationships to self-interested freedom is to assert that marriage 'is a reality that is prior to love'. ${ }^{16}$ The institution of marriage, he thinks, provides the structure necessary to shape the character and identities of men and women in such a way to enable them to sustain authentic intimate relationships. In this way, marriage provides the proper context for sexual relations. Similar to Meilaender, Hauerwas criticizes James Nelson for grounding his sexual ethics on abstract concepts like 'faithfulness'. But rather than emphasising biological 'difference' as an

\footnotetext{
${ }^{13}$ Ibid., 129.

${ }^{14}$ Hauerwas, 'Sex in Public', 486.

${ }^{15}$ Ibid., 487.

${ }^{16}$ Ibid., 488.
} 
alternative ground for sexual relationships, Hauerwas focuses on specific practices that he thinks are inherent to marriage, emphasising in particular the view that procreation is an essential element of sex. Marriage 'rightly orders' men and women, and thus it 'rightly orders' sex. Following Rosemary Haughton, Hauerwas describes Christian marriage as 'heroic' because 'the couple dedicate themselves, not simply to each other, but to work together at something greater than I imagine' ${ }^{17}$ To achieve such 'heroism', Hauerwas continues, requires that couples avoid self-centred considerations, such as whether they are 'fulfilled' in their relationship. He argues that 'Christians do not believe that love legitimates sex or even that sex is an expression of love. ${ }^{18}$ Instead, marriage becomes a sign of hope, because it is lived in expectation of welcoming in new lives in the form of offspring. On this point, Hauerwas pulls no punches, 'Accordingly it would be appropriate as part of the examination of couples desiring to have the Church witness their marriages to have their intensions to have children declared.'

The contribution of theologians discussed thus far is how they highlight ways in which so-called 'liberal' sexual ethics can often revolve around rather vague and sentimental concepts, which merely mime the wider culture's emphasis on individual free choice. ${ }^{19}$ This critique is achieved, however, at the cost of jettisoning the moral significance of any relational elements such as joy, gratitude, even love. ${ }^{20}$ This is due to the view dominant cultural values like individual choice and freedom need to be challenged by Christian ethics. Thus, for these theologians, it is biological identity - conceived of either as 'difference', the capacity to procreate, or as bodies disciplined by communal practice - that serves as the ground for a Christian ethic of sex. In effect, the antidote for individual subjective motivations in sexual relationships is to render as morally irrelevant the individual subject as anything more than bodily material. Making the subjectivities of the individuals involved in a sexual relationship pointless (their motivations, intentions, enjoyment), however, ultimately undermines the capacity of such theologies to serve as an 'ethics' for contemporary human subjects. There is no relational component to such a theology of sex; there is, in effect, no sexuality, but mere biological act: vaginal insemination. What remains lacking is substantive

\footnotetext{
${ }^{17}$ Ibid., 500.

${ }^{18}$ Hauerwas, 'Resisting Capitalism: on Marriage and Homosexuality', A Better Hope: Resources for a Church Confronting Capitalism, Democracy, and Postmodernity (Grand Rapids, MI: Brazos Press, 2000), 49.

${ }^{19}$ For a similar criticism of the 'situation ethics' of Joseph Fletcher, see: Mark D. Jordan, The Ethics of Sex (Oxford: Blackwell, 2002), 144-6.

${ }^{20}$ Kathleen Roberts Skerrett makes a similar observation about the approach to sexuality in new natural law theory; see: 'Sex, Law, and Other Reasonable Endeavours', differences 18.3 (2007), 81-96.
} 
concern for relational connection, physical pleasure, or emotional joy. It is sex cleansed of the messiness of particular individual human beings. While the arguments above are presented as if they are based on a deep respect for embodied reality, this is only possible due to the way in which embodied particularity is reduced to either one of two concerns: which genitalia the individuals in question have, or whether the proper institutional force is shaping embodied experience.

At the most basic level, these approaches are not primarily grounded on a Christian theological position, in the sense of focusing on biblical treatments of sexuality, or on substantive doctrines such as that of creation. The moral arguments of both Meilaender and Hauerwas could be accused, in the end, (to use a phrase Hauerwas often employs) of being materialist 'all the way down'. For Meilaender, it is the materiality of empirical biological difference that gives moral dignity to sex; according to Hauerwas, it is the character-instilling structures of the ecclesial institution of marriage, and it alone, which enables the sex act (in the singular) to be grace-filled. It is notable that this is an ethic of sex without a pneumatology. For Hauerwas, for example, the 'church' (Which church? Whose perspective within it?) is the agent assigned as the guardian of sexuality through the institution of heterosexual marriage, leaving little space for either a divine or human agent to contribute something to the relationship. The extent which his moral theology is grounded on contextual determinism is clearly evident in his suggestion that true marriage is not possible within capitalism. ${ }^{21}$ It seems that Hauerwas fears that capitalism is capable of entangling even the movement of the Spirit when it comes to sexual relationships. To this concern about the power of capitalism to shape sexual relationship the discussion now turns.

\subsection{Choosing not to Choose: the Demonisation of Choice}

In the approaches to sexual ethics discussed thus far, considerable critical attention is given to illuminating the interconnection between cultural attitudes to sexuality and the values of liberal individualism. This is then shown to be closely associated with capitalist economies. For Hauerwas, capitalism undermines Christian marriage because it prioritises personal self-interest and free choice. Sexuality gets reduced to a contract, he suggests, which reduces men and women to erotic consumers who are out simply to accumulate as much sexual capital as possible in a competitive market. Oliver O'Donovan's raises similar concerns in his reflections on the ethics of artificial insemination. According to O'Donovan,

\footnotetext{
${ }^{21}$ Ibid., 51.
} 
accepting the use of procreative technology reduces procreation to 'instrumental means chosen by the will'. ${ }^{22}$ It turns procreation to a 'product' of human choice, rather than recognise it as an intrinsic good beyond the control of individual self-interest. In this way, the technology mimes the cultural values of industrial capitalism.

These theologians raise important concerns about the ways in which social context influences values and behaviour. Renata Salecl, a Slovenian philosopher and sociologist, has analysed the ways in which the structures of liberal capitalism shape human subjectivity and culture. ${ }^{23}$ A prominent theme in her writing is the psychological dynamics related to the offer of limitless choice, which many imagine is what it means to be 'free'. Salecl argues that such freedom of choice invariably becomes experienced as an encounter with ever new prohibitions, which individuals often generate for themselves. The basic dynamic can be summarised as follows: the more I am granted freedom of choice, the more I must impose self-mastery upon myself in order to ensure that I achieve what it is I want. One example from the sphere of sexuality that Salecl explores is taken from contemporary dating practices. ${ }^{24}$ She analyses in particular the 'hook-up' culture in American colleges and universities (and increasingly, one might add, in secondary schools). The phenomenon of the 'hook-up', or casual sexual encounter, can be understood as the evolution of the sexual revolution of the 1960s. It essentially has to do with freedom of choice without restrictions and prohibitions. Investing much emotional attachment into the equation is considered an unnecessary burden and an impediment to total freedom. The paradox that Salecl illustrates, however, is that, contrary to this emphasis on choice and control, hook-up culture often 'increases feelings of insecurity, anxiety and guilt'. ${ }^{25}$ Treating sexual partners as disposable objects generally leads people to eventually feel disposable themselves. Moreover, if one can choose to hook-up, then the expectation becomes that one will in fact 'hook up'. The freedom to choose casual sex becomes the expectation that one will choose casual sex. Those not pursuing such relationships (or themselves being pursued) are left to wonder: 'What's wrong with me?' Freedom, in such an environment, generates its own anxieties and prohibitions.

\footnotetext{
${ }^{22}$ Oliver O’Donovan, Begotten or Made? (Oxford: Clarendon, 1984), 39.

${ }^{23}$ Some notable representative work includes: Renate Salecl, The Spoils of Freedom: Psychoanalysis and Feminism after the Fall of Socialism (London \& New York: Routledge, 1994); (Per)versions of Love and Hate (London: Verso, 1998).

${ }^{24}$ Renata Salecl, The Tyranny of Choice (London: Profile Books, 2011), chapter 3.

25 Ibid., 77.
} 
Salecl wants her audience to recognise what many people living in liberal capitalist societies often fail to acknowledge: 'something is always lost when we choose'. ${ }^{26}$

Despite being attentive to some of the challenges with which contemporary culture presents to Christian sexual ethics, however, the theologians discussed above argue as if they themselves, along with the church, can be free from the dynamics of capitalism and modern individualism. One might summarise this approach as an argument that asserts that, by choosing not to choose, Christians escape the dilemmas of free choice. This slippage in argumentation reveals that important issues remain to be addressed. On this point, an observation by Mark Jordon is pertinent. He argues that many Christians rely on stereotypes in order to shift the blame for their confusion over sexuality to sources outside of the Church. When guilty of this, he counsels, 'we Christians would do better not to excuse ourselves so quickly. ${ }^{27}$ This suggests that the question to be asked of the Christian theologians examined thus far is: are they too quick to shift the blame for the church's difficulties over sexual ethics to the liberal emphasis on freedom of choice? Here the point is not that the ideal of freedom of choice is unproblematic - which Salecl's analysis clearly challenges - but simply that placing the blame on liberal modernity for the failings of Christian sexual ethics is a rather convenient scapegoat for the limitations in Christian theology and practice.

What distinguishes the Christian ethicists under consideration here is their tendency to conclude that rejecting the ideals of freedom and choice is the only antidote for the troubles of sexual ethics. Sexual decisions cannot, according to Hauerwas, be left to individual Christians, for they display a painful tendency to adopt the corrupting habits of the liberal individual. One escapes from this situation by having one's subjectivity appropriately 'trained' by the Church; 'In order to know and worship God rightly, we must have our desires transformed' by the practise of the ecclesia. ${ }^{28}$ Because freedom to choose is problematic, Christian sexual ethics needs to provide a firm alternative structure to contain the chaos, be it through biological empiricism or ecclesial discipline.

Defining Christian sexual ethics in opposition to liberal freedom, however, results in a solution that is merely the opposite side of the same coin. The simplistic caricature of the traditions of the liberal Enlightenment is challenged by forwarding a simplistic caricature of the purity of the Church's own internal workings. But the inadequacy of this antidote is

\footnotetext{
${ }^{26}$ Ibid., 93.

${ }^{27}$ Jordan, The Ethics of Sex, 5.

${ }^{28}$ Hauerwas, The Peaceable Kingdom: A Primer in Christian Ethics (University of Notre Dame Press, 1991), 14.
} 
painfully obvious in a context of ongoing revelations of sexual abuse by clergy. Both simplistic narratives (the chaotic external 'Liberal Paradigm' and the 'purity of the Church') shun the difficulties inherent to a mature ethics, which involves discerning how to make complex choices, as well as learning to live with the impact of these same choices.

Given that choice is unavoidable in sexual ethics, the question of the process and operative factors shaping individual choices is an important issue. The sociologist Eva Illouz notes that six cultural components, involving both cognitive and emotional processes, shape what she calls the 'architecture of choice': (i) one's consideration of the consequences of one's actions, (ii) the process of consultation with relevant authorities, (iii) modes of selfconsultation, (iv) cultural norms of suspicion regarding wants and desires, (v) the accepted grounds for making a decision, and (vi) whether choice is valued for its own sake. ${ }^{29}$ Illouz observes that the significance as each of these components, along with their specific content, has shifted over time. For example, in pre-modern courtship, whatever emotions one had about a potential partner had to be organised with particular attention to one's social and economic interests (particularly in the case of women). Social standing, dowries, and economic alliances were thus considered primary considerations for selecting partners. What has occurred in the modern period, Illouz continues, is an ever-increasing process of disembedding individual romantic choices from the moral and social fabric of established traditions and groups, which has resulted in shifting priorities and considerations constituting the architecture of choice.

Conceived in these terms, one can describe the arguments of Hauerwas, Meilaender and O'Donovan as seeking to restrain individual choice regarding sexuality within certain parameters, with particular emphasis on church expectations and norms (Illouz's points (ii) and (v)), while challenging modernity's increasing appreciation of choice as a moral good of its own (point vi), and individual preferences and emotions (point iii).The dynamics of choice are thus not eliminated from moral reasoning in their work, but only limited in scope.

The principal contribution of the work of these theologians is to heighten attention to the social location of sexual ethics, and alert Christians to the reality that their choices and assumptions occur within the context of their local culture. At the same time, these theologians imply that these challenges are essentially external to the Church's own teaching and its membership. Rather than focusing on analysing the numerous challenges contemporary Christians must navigate as they operate within the current parameters of

\footnotetext{
${ }^{29}$ Eva Illouz, Why Love Hurts: A Sociological Explanation (Cambriodge, Polity, 2012), 20-21.
} 
modern culture's architecture of choice, such theologians consistency imply that Christians ought to opt out of such dangers by submitting to the disciplining practices of the ecclesia (or to the essential nature of their biology) and thus elude the perils of individual decision making.

\subsection{Fetishising Choice: emphasising the importance of context without critically analysing it}

If the conservative theologians discussed above fail to offer a convincing response to the challenges of contemporary sexual ethics, it is noteworthy that liberal Christian ethicists often uncritically adopt the modern celebration of individual freedom, without attending sufficiently to the social and cultural tensions found in contemporary sexual practices. Mileander and Hauwerwas have already alluded to James Nelson's privileging of 'love' as the foundation for Christian sexual ethics, which establishes individual emotional and cognitive considerations as the primary components of moral choice. ${ }^{30}$ Such an emphasis on the freedom of the individual as normative for sexual ethics is common among liberal theologians. ${ }^{31}$ Yet a contradictory tension is often perceptible in such perspectives. As they defend the need for theology to take serious account of contemporary culture and context, such theologians often uncritically adopt a number of values and assumptions contained within this context. Essentially, they do not reflect deeply on their own modern cultural context, but simply mime it. Such theology fails to scrutinise the social forces shaping individual personal choices. If conservative Christian sexual ethicists often demonise individual freedom of choice, liberal theology has a tendency to fetishise such freedom. Greater critical scrutiny and social analysis is required on the part of liberal theologians, in order to uncover how the current economic and social environment shapes cultural values and practices. For example, many sociologists are concerned with the ways in which the concept of sexual freedom places a far greater burden on women than men, ${ }^{32}$ and with the fact that the very proliferation of choice can often be experienced as disempowering and emotionally disorienting. ${ }^{33}$

Sarah Coakley calls for an ethics of sex that ceases to be constructed according to a simplistic antagonism between freedom and sexual morality; one that moves 'beyond and

\footnotetext{
${ }^{30}$ James B. Nelson, Embodiment: An Approach to Sexuality and Christian Theology (Minneapolis: Augsburg, 1978).

${ }^{31}$ See, for example: Beverly Wildung Harrison, Making the Connections (Boston: Beacon Press, 1992);

Marcella Althaus Reid (ed), Liberation Theology and Sexuality (London: SCM, 2009).

${ }^{32}$ Illouz, Why Love Hurts, 247.

${ }^{33}$ Renata Salecl, On Anxiety (London: Routledge, 2004).
} 
through the false modern alternatives of "repression" and "libertinism"., 34 Thus far, the discussion in this essay has done much to illustrate why such a goal is required. A Christian ethic of sexuality that is adequate to the challenges facing the churches needs to attend to the concerns of both poles of this debate. It should recognise the problems inherent to the concept of freedom that are articulated by conservative Christian ethicists, but also acknowledge the liberal recognition of the contributions of modern culture and of the complexity of individual subjectivity. The following section turns to two theologians who make important contributions in this latter direction.

\section{Towards a Theology of Sexuality}

\subsection{The Body's Grace, Desiring the Other's Incarnation}

The article 'The Body's Grace' by Rowan Williams is noteworthy for the consistent way that, after admitting that the quest for an adequate sexual ethics is 'doomed from the start', he then refrains from introducing a simple answer to the problem. Instead, Williams turns to analysing why it is that sexuality is so difficult to comprehend and why, as he puts it, it 'matters' ${ }^{35}$ To explore this problem, he turns to Paul Scott's four novels of The Raj Quartet, and particularly to the character Sarah Layton, a respectable daughter of a colonial official, who tries to live truthfully and generously in the midst of a corrupt and racist regime, despite feeling powerless and vulnerable. When she is seduced, her Indian lover observes that, 'You don't know anything about joy at all, do you?' She is lost, a young woman in a foreign culture where she is viewed as an occupier; she is 'present fully to no one and nothing'. Following the sexual seduction by her partner, however, even though one could not say that 'true love' was part of the equation, Scott describes a scene in which she looks into the mirror and has an epiphany; 'she had entered her body's grace'. ${ }^{36}$

For Williams, this narrative is illuminating. Although the story is far from a sentimental romance (it includes pregnancy, an abortion, and continued loneliness and disappointment), Williams observes that the transformation brought about by Sarah's experience of her 'body's grace' remains deeply resonant and formative. Through her sexuality, 'a frontier had been passed'; she had become 'present' to herself in a new way; 'an entry into some different kind of identity'. Even though she continues to be alienated from

\footnotetext{
${ }^{34}$ Coakley, 'Rethinking the sex crises', part 3.

${ }^{35}$ Rowan D. Williams, 'The Body's Grace', Theology and Sexuality: Classic and Contemporary Readings, ed. Eugene F. Rogers, Jr. (Oxford: Blackwell, 2002), 310.

${ }^{36}$ Ibid., 311.
} 
her surrounding - she still doesn't really belong - she feels a new confidence in herself and of value. Despite the messiness and complexity of her sexual experience, Williams thus perceives a profound significance and depth. The result is a perspective on sex which - far from focusing on biological givens, or on a regime of power that exclusively shapes individual subjectivity - is prepared to be surprised by sexuality's capacity to transform a life with lasting effect. Williams links this with a spiritual experience, 'Grace, for the Christian believer, is a transformation that depends in large part on knowing yourself to be seen in a certain way: as significant, as wanted.'

This emphasis on how the body can be the cause of happiness highlights the superabundance of sexuality, which surpasses the more immediate and tangible 'productions' of sex, be they reproduction, strengthening communal bonds, even pleasure. Williams highlights a deeper and more intimate function of sexuality. Being desired, one gets caught up in a dynamic similar to that outlined in the stories of creation, incarnation and incorporation into the fellowship of the Body of Christ. According to Williams, this narrative 'tells us that God desires us, as if we were God'. This desiring of a human creature becomes the cause of another's desire; 'we are pleased because we are pleasing'. ${ }^{37}$ Such a location of sexual expression within the horizon of divine grace is what Sarah experiences in the $R a j$ Quartett. Her sexual experience is complicated - both pleasurable and disappointing - yet at the core of her sexual life is an experience of acceptance and gift, which transcends the dominating regimes and external forces shaping her life (patriarchy, colonialism, racism, and, yes, capitalism).

Williams labours to head-off the possible misunderstanding that such a perspective opens the door to narcissistic self-love, of the kind that concerns Hauerwas, Meilaender and O'Donovan. He thus emphasises how the movement of desire he describes is dependent upon being recognised by the object of desire. It is not simply that Sarah feels herself to be graced; she feels graced by being desired by the lover. Williams thus concludes: 'this means that in sexual relation I am no longer in charge of what I am.... I cannot of myself satisfy my wants without distorting or trivializing them.' This suggests that 'distorted sexuality' is what emerges when one attempts to maintain control over one's own happiness and joy, and through refusing to risk permitting one's body to be seen in the light of the other's perception. Such a distortion, in the form of refusal to accept a loss of control by the individual ego, results in the form of self-love that Hauerwas and his colleagues are quite

${ }^{37}$ Ibid., 313 (emphasis in original). 
right to warn against. When one person controls another without regard for the other's desire, then the sexual relation, according to Williams, cannot be grace-filled.

When one recognises this dynamic, Williams continues, one understands that decisions about sexuality are fundamentally decisions about how one engages with the body in making sense of the world. Conventional heterosexual marriage is a context in which this is often nurtured. But because marriage is such a cultural convention, it is easy for Christians not to recognise the underlying fundamental nature of sexuality, for they simply follow the one conventional option available to them. What is noteworthy about homosexual relationships, according to Williams, is the way in which they highlight the question of the meaning of desire. Lacking the self-evident utilitarian function of reproduction, same-sex relationships bring immediately into view the dynamics of desire present in all embodied relationships.

Kathleen Skerrett has written appreciatively on Williams' essay, but she places additional emphasis on the object of one's desire. Drawing from Roger Scrutin's suggestion that sexual desire is not so much directed toward another's body, but rather towards her or his consciousness, Skerrett argues that, 'In erotic longing, one desires another's incarnation' ${ }^{38}$ She emphasises the notion that sexual desire entails mutual kenosis: 'I want to be poured out incarnate in response to the reciprocal pouring out of the other toward me.' Both she and Williams thus focus on the inter-subjective nature of sexual relations. The imagery Williams employs highlights how the individual subject experiences 'grace' by being desired. Skerrett's theological metaphor focuses attention on the 'gracing' of the other. Whereas the concept of the 'body's grace' emphasises the individual's own sense of being of incommensurable value, the idea of 'desiring the other's incarnation' evokes a deep connection to another consciousness.

Together, both of these accounts restore moral dignity to relational qualities such as joy, pleasure, and honesty. As shown above, these elements are often marginalised in Christian sexual ethics. But it is precisely at this point that conservative theologians might interject and argue that Williams and Skerrett are simply following a path well-worn by liberal theologians. Such an accusation might be constructed in the following manner: after acknowledging that the dynamics of sexual desire are complicated and messy, is sexual desire now being presented as the solution to the messiness? In other words, is the cause of the disease also being presented as the cure? Andrew Cameron, for example, asks whether the

\footnotetext{
${ }^{38}$ Skerrett, 'Sex, Law and Other Reasonable Endeavours', 92 (emphasis in original).
} 
interpretation of Sarah's experience offered by Williams is 'fatalistic'? Cameron notes that Williams does not provide any basis to hope that Sarah might 'know "the body's grace" in the best possible way' - i.e. without fear that betrayal or rejection might undo the logic of grace. ${ }^{39}$ Such a challenge asks whether Williams neglects the darker elements of sexual desire. Human desires can often be in conflict, and sexual experiences not only have the capacity to fill one with a sense of grace, but also with profound grief, pain, and devastation. The desire of the other might lead one to experience 'the body's grace', but all too often its encroachment brings alienating objectification - becoming more dis-incarnating that incarnating.

Such criticism admittedly reveals some gaps in the accounts of Skerrett and Williams. Nevertheless, the accusation that they idealise sexual desire is exaggerated. Skerrett, for example, has criticised versions of feminist theology that neglect what she calls the "tragic view of eros'. ${ }^{40}$ Such disregard, she says, occurs when a theological ethic is constructed on the basis of a sentimental concept of erotic 'right-relation'. She also criticises relational categories like 'mutuality' when they are described as having the capacity to dissolve the boundary between self and other. For example, when Beverly Harrison and Carter Heyward employ the concept of 'erotic power', they argue the following: 'Even some of the most subtle feminist theory has not yet adequately repudiated the association of eroticism with the split between self and other that is endemic to the patriarchal view of reality. ${ }^{, 41}$ Against this call for the elimination of boundaries, Skerrett argues that it is necessary to recognise that desires between different individuals can often be in conflict. As one learns in the Raj Quartet, not everyone that Sarah desires will desire her back. In When Boundaries Betray Us, however, Heyward argues that her therapist's refusal to accept a sexual relationship with her was the result of the therapist's refusal of 'mutuality'. ${ }^{42}$ In response, Skerrett suggests that Heyward is denying her therapist the right to not to return her desire. By contrast, Skerrett argues that a 'tragic' understanding of eros recognises that 'renunciation - bearing the no of the beloved - is not antisensual aestheticism: it is one of the positive disciplines of love' ${ }^{43}$

\footnotetext{
${ }^{39}$ Andrew Cameron, 'Desire and Grace: Williams and the Search for Bodily Wholeness', On Rowan Williams: Critical Essays, ed. Matheson Russell (Eugene, OR: Cascade, 2009), 154.

${ }^{40}$ Kathleen Roberts Skerrett, 'When No Means Yes: The Passion of Carter Heyward', Journal of Feminist Studies in Religion 12.1 (1996), 71-92.

${ }^{41}$ Beverly Harrison \& Carter Heyward, 'Pain and Pleasure: Avoiding the Confusions of Christian Tradition in Feminist Theory', Christianity, Patriarchy and Abuse, ed. Joanne Carlson Brown and Carole R. Bohn (New York: Pilgrim Press, 1989), 165. Quoted in Skerrett, 'When No Means Yes', 72.

${ }^{42}$ Carter Heyward, When Boundaries Betray Us (San Francisco: Harper, 1993).

${ }^{43}$ Skerrett, 'When No Means Yes', 91.
} 
Thus, far from advocating a sentimental understanding of sexual relations, Skerrett is sensitive to the difficulties and tensions inherent to them. Williams offers similar caution when he acknowledges that, 'Nothing will stop sex from being tragic and comic. ${ }^{44}$ One might be rejected, betrayed, disappointed, or simply made to look foolish.

Far from being naive and sentimental about sexual desire, Williams and Skerrett are alert to the dangers and risks inherent to it. To acknowledge this humbles any impulse to romantically over-estimate the relational power of sexuality. A caution Williams offers in another context about the use of the concept 'incarnation' is relevant here. While criticising the idealisation of the 'incarnational principle' in Anglican theology, he argues that overemphasising the fusion of heaven and earth results in 'slippage into ideology' ${ }^{45} \mathrm{Such}$ a problem emerges when talk of God's presence suggests that the divine is immediately accessible and knowable. This arises when one equates divine grace with sexual relations as such, or when it is suggested that a feeling of intimacy is equivalent to the fullness of divine presence.

While neither Skerrett nor Williams engage in such mystification, one can understand why theologians like Hauerwas, Meilaender and O'Donovan are nervous when human and divine action are spoken of as operating intimately within human relationships. Perhaps it is for this reason that Williams has subsequently distanced himself from his essay 'The Body's Grace' (although, significantly, without dismissing it). ${ }^{46}$ Although this equivocation may simply be due to the fact that he was subsequently serving as Archbishop of Canterbury in the midst of an intense dispute over homosexuality within the Anglican Communion, he also subsequently offered a theological point of clarification: 'Ethics is not a matter of a set of abstract rules, it is a matter of living the mind of Christ. That applies to sexual ethics; that is why fidelity is important in marriage. ${ }^{47}$

This reference to the mind of Christ is a significant one for a Christian ethics of sex, but what it means is not immediately straightforward. At first glance, the reference to Christological doctrine appears to offer greater concrete particularity than Skerrett's poetic

\footnotetext{
${ }^{44}$ Williams, 'The Body's Grace', 314.

${ }^{45}$ Rowan Williams, 'Beginning with the Incarnation', On Christian Theology (London: Blackwell, 2000$), 85$.

${ }^{46}$ In an interview with the Dutch newspaper Nederlands Dagblad, Williams suggested (without elaboration) that some points of criticism of his essay were appropriate, and that one should not interpret his comments as open support for 'inclusion' in the church. See: Williams, 'The Church is Not Inclusive', http://www.clarionjournal.com/clarion_journal_of_spirit/2006/09/ welcome_versus_.html [accessed 30/08/2012]. It is noteworthy, however, that in an interview with Time Magazine in 2008, he said of his same essay, 'I still think that the points I made there and the questions I raised were worth making as part of the ongoing discussion.' See: http://www.time.com/time/ magazine/article/0,9171,1630234,00.tml\#ixzz258r251X8 [accessed 30/08/2012]. ${ }^{47}$ Williams, 'The Church is Not Inclusive'.
} 
deployment of the concept of 'incarnational' relationship. The statement could be read as resonating with Hauerwas' concern that Christian ethics be conceived in terms of the Christian narrative story rather than as grounded in moral 'principles'. It would be a mistake, however, to reduce William's reference to 'the mind of Christ' to some precise 'practice' or 'grammar' that human subjects are to mimetically repeat in a straightforward manner.

Skerrett's work helps one appreciate why this is so. On the challenge of living within the constraints of moral decision making, she writes, 'The tenderness and excruciations of finitude are something you can only learn by living them, not by hearing about them. ${ }^{48}$ In the same way, Williams' care in defending the moral task of living the mind of Christ, rather than merely copying or adhering to Christ's 'mind' (as if such a thing were accessible to the Christian), is to be understood as a mode of aspirational seeking - or, better, patient awaiting - rather than as a specific programme of obedience. Mark Jordan captures this spirit when he notes: 'revelation teaches in ways that bureaucracy cannot' ${ }^{49}$

Framed doctrinally, at stake is the classic distinction between justification and sanctification. The church undertakes the former practically through grateful reception of free grace; the latter is often sought through teaching instruction. Is a Christian ethic of sex primarily to be approached as a pedagogical matter, for which the Church's principal calling is to engage in instruction and formation, or is the more fundamental task for moral theology to recognise and give thanksgiving for the revelatory gift that is received and grasped in terms of the 'body's grace'? For Hauerwas in particular, but also for Meilaender and O’Donovan, sexuality is a matter for which the Church must offer distinctive teaching and disciplined formation. The church and its 'practices' (or 'institutions') shape and give proper form to sexuality. Williams and Skerrett, however, without discounting the power of embodied practice, focuses instead on the elements of surprise, gift, and interruption in human sensual experience. For them, human sexuality, in the sense that it involves embodied response to another, is precisely the vehicle through which human beings encounter God's revelation.

\subsection{Sexuality and Prayer}

It is noteworthy to observe how, when wrestling with sexual ethics, both Mark Jordan and Sarah Coakley turn to a discussion on the nature of prayer. Jordan observes, for example,

\footnotetext{
${ }^{48}$ Kathleen Roberts Skerrett, 'Roundtable: Negotiating Feminist and Gender Studies', Journal of Feminist Studies in Religion 26.1 (Spring 2010), 129.

${ }^{49}$ Jordan, The Ethics of Sex, 171.
} 
how the phenomenology of prayer closely resembles that of erotic relationships. Both involve fluctuations in one's sense of intimacy and connection. The intensity of one's presence to the other - be that either to God or to the beloved - wax and wane in creaturely life. This reality is due to the nature of human finitude, but more precisely, Jordan understands it as being related to the fact that all forms of intimacy are construed in relation to power. ${ }^{50}$ Human creatures continually struggle to maintain the difficult balance between self-control and being receptive of what lies beyond their mastery. This leads to constant fluctuations of reaching out and pulling way - the wax and wane of intimacy - so that one's love cannot be fully possessed or integrated into the self.

Coakley describes prayer and contemplation in a similar manner, arguing that prayer is only empowering when one ceases to set the agenda and 'make space' for God to be God. ${ }^{51}$ This is a mode of engagement on the part of the subject which does not insist on domination or control, while at the same time avoiding the mere adoption of vulnerable powerlessness or meek submission. For Coakley, this form of 'spiritual practice', which is dedicated to 'attending to the other', sheds light on the ways in which institutions and others 'discipline' us, without neglecting the fact that we also 'have the power to discipline ourselves'. ${ }^{52}$ She develops this line of thinking to describe the Christian life as a life-long process involving the purification and redirection of desire towards the divine. This fosters an 'eschatologicallyoriented' subjectivity that seeks to be ever more transformed into the divine life. ${ }^{53}$ Here one observes the theological distinction between justification and sanctification being brought back into harmony in the practices of prayer and contemplation. Skerrett helps clarify how this is so in relation to sexual desire:

the lived experience of sexual desire redresses our political accounts of autonomy. I am immediately constrained by my "choice" of object at levels that prodigally exceed my intentions. One does not choose an object of sexual desire; one suffers desire for the other, the way one suffers grief. Did I "consent" to this? ${ }^{54}$

This reflection on the nature of sexuality offers a more sophisticated and illuminating approach to contemporary Christian sexual ethics than do the writings of Hauerwas, O'Donovan and Mileander, particularly with regard to the question of human agency and

\footnotetext{
${ }^{50}$ Jordan, The Ethics of Sex, 168.

${ }^{51}$ Sarah Coakley, Power and Submission: Spirituality, Philosophy and Gender (Oxford: Blackwell, 2002 ), 34.

${ }^{52}$ Ibid., xvii-xviii.

${ }^{53}$ Ibid., 164.

${ }^{54}$ Skerrett, 'Sex, Law and Other Reasonable Endeavors', 92 (emphasis in original).
} 
freedom. Yet, although Skerrett and Williams avoid the liberal tendency to idealise individual freedom of choice, there is a sense in which their careful attention to the phenomenological dynamics of inter-personal relationships remain somewhat two-dimensional. They have shifted the discussion away from a subjective individualism to one more that is alert to intersubjective relationality. What remains to be done is further analysis of the social and cultural forces shaping individuals as the exercise their freedom (which, in their essays on sexuality, neither Williams nor Skerrett discuss in any great detail). Some initial reflection in this direction is supported by turning to a narrative account that illustrates the importance of including such considerations in sexual ethics.

\section{Freedom of Choice, Sexuality, and Capitalism}

The complicated connections between sexuality, love, the freedom to choose, and contemporary culture are at the heart of Jonathan Franzen's novel Freedom. ${ }^{55}$ The book focuses on a contemporary middle class American family: Patty and Walter Berglund, and their two children Joey and Jessica. The narrative follows how each of the characters runs headlong into the deep contradictions and painful tensions inherent to the freedom of choice, and it explores how these issues impact on their most intimate relationships.

The complexity of love and sexuality emerge at the very outset of the relationship between Patty and Walter. Patty isn't initially attracted to Walter when she meets him in college, but to his more dynamic roommate Richard. When Patty does begin a relationship with Walter, she often finds him tedious and routine, but she is also profoundly affected by how she feels perceived by him: he had 'a blind faith in her goodness which ... she had rather desperately come to count on' (120). Throughout her life, Patty is free to choose between various possible partners, but she does not know how to make good choices.

A common pattern thus emerges in the novel. Patty is attracted to Walter because of his intense admiration of her; her son Joey begins a sexual relationship with his neighbour Connie largely because she is completely devoted to him, and Walter is seduced by his assistant Lalitha, who he believes to be "the one person who wanted him without qualification' (465). The narrative illustrates how, when sexual desire is rooted in this kind of dynamic, it inevitably begins to wane. While initially Patty is excited by seeing herself in the image that Walter has of her, she continually feels plunged back into her 'unpretended true

\footnotetext{
${ }^{55}$ Jonathan Franzen, Freedom (San Francisco: Harper Collins, 2010). Subsequent references to this novel are found in parentheses.
} 
self' (107). Try as she might to be free of her past, her less attractive qualities, and her own unresolved emotional difficulties, these issues cannot be buried forever, even when they remain invisible to Walter's adoring gaze. She is never really able to believe that Walter loves her for who she 'truly' is. Her son Joey is involved in a similar situation with Connie. He both enjoys the attentions of Connie's 'boundless capacity for idolatrous love', but also considers it too intense and misplaced (288). Likewise, when Lalitha kisses Walter with 'more desire for him in her mouth than in Patty's entire body' (336), it initially fills him with an intense feeling of joy; however, he soon finds that although 'he now had what he wanted, ...it was making him lonely' (467). What is clear in the lives of these characters is that desire is far from a reliable compass for moral discernment or the achievement of happiness.

Such oscillations of desire are at the core of Franzen's examination of freedom. Connie tells Joey that he should feel free to sleep with other women while he is away at college, but when he does he feels like he has betrayed both himself and his girlfriend. He himself is consumed by jealousy when Connie begins to have sex with another man. The closer he gets to the object of his fantasy - the beautiful Jenna - the more miserable he becomes. Jenna, he realises, 'didn't understand love' but simply measured her life in terms of money and cultural status (408). Joey rebels against his parents, and initially against Connie, determined to be free to do whatever he wants, only to discover that he 'didn't know what to do, he didn't know how to live' (318).

This narrative thus interrupts tendencies to celebrate both the capacity of passionate desire to achieve right-relationship, but also the notion that firm discipline and authority resolve the tensions of sexuality. Regarding the former tendency, Patty laments how her brief affair with Richard made her miserable: 'I've spent three years wanting a thing I knew would never make me happy. But it didn't make me stop wanting it' (375). Regarding the second tendency, the more Patty and Walter try to influence and shape Joey's life, the more he aggressively rebels and longs to be 'free'. Many of his choices simply become motivated by his determination to choose the opposite of what his parents represent.

The dynamics of these relationships resonate with Skerrett's recognition that 'choice' often exceeds one's intentions. It also recalls Williams' observation that desire is a phenomenon that can interrupt and surprise the subject. These two theologians emphasise the positive and life-giving potentials of this dimension of sexuality, even as they acknowledge the tragic risks it entails. Franzen's portrait of the Berglund family deepens this trajectory by illuminating how the dynamics of desire can elude the control and even awareness of individual subjects. Moreover, the novel demonstrates ways in which consumer capitalism 
has become intertwined with contemporary cultural understandings of sex. Franzen portrays this in a rant by Richard as he describes some of his music groupies: 'Me me me, buy buy buy, party party party' (202). Walter adds a political dimension to this: 'Capitalism can't handle talking about limits, because the whole point of capitalism is the restless growth of capital' (361). The novel suggests that the impermanence and constant flux of capitalism shape the exercise of individual freedom in profound ways, encouraging impatience, selfcenteredness, and temporary relationships.

When Patty visits her daughter's college, she reads the institutional motto on the wall, Use Thy Freedom Well (184). But the novel shows how difficult it is for any of the main characters to live either freely or well. They all resent the limits and frustrations they experience in their lives. At the same time, they find moments of apparent free choice to be disorienting and disappointing. Illouz notes that such experiences are a common feature of contemporary sexuality: 'Suffering in contemporary intimate interpersonal relationships reflects the situation of the self in conditions of modernity'. ${ }^{56}$ Franzen's narrative shows how, over time, the main characters learn to cope with their constraints and disappointments. They must come to appreciate that part of this task involves unlearning some of the cultural conditioning they have received, as well as resisting social pressures to act in certain ways.

At the heart of the novel is the troubled relationship between Patty and Walter. Patty often finds sex with Walter unexciting, partially due to his gentle attentiveness (which is paradoxically one of the things she loves him for). Meanwhile, she burns with desire for Richard. Over time, as Walter's patience with Patty's frustrated state wears thin, he finds the desire that Lalitha has for him energizing. When Patty admits her brief affair with Richard to Walter, he uses this as an excuse to exile her from his life. Patty is then "free" to be with Richard, and Walter is "free" to enjoy his new life with Lalitha. What the novel demonstrates is that such escapes to the fantasy of sexual bliss are not possible. For Walter, 'it didn't feel like liberation, it felt like death' (480).

The breakthrough for both characters comes when each is able, not only to see themselves for who they truly are, but also to accept this. This is matched by a new capacity to perceive the other clearly for who they are, and to nevertheless love them. This achievement does not come easily. The first movement in this direction occurs when Walter discovers Patty's personal journal. When Walter reads it, even though this results in considerable pain for all involved (and also in the breakup of the marriage), the event enables

\footnotetext{
${ }^{56}$ Illouz, Why Love Hurts, 16.
} 
a new level of truthfulness to enter into their relationship. It takes some time for Walter to absorb the impact of these discoveries, aided by criticism he receives from his daughter. He admits that he must also engage in some self-critical exploration, and determine whether he is becoming 'another overconsuming white American male who felt entitled to more and more and more' (318).

These events prepare the ground for a breakthrough in the drama, but what finally enables it is Patty's refusal to give up on the relationship. She recognises her own failings in the wake of the death of her father, as she realises that her own 'dream of creating a fresh life, entirely from scratch, entirely independent, had been just that: a dream' (514). Accepting this, she experiences a change in herself. She is able to let go of her fantasy of an endlessly exciting life with Richard, as well as her resentment of the disappointments she has suffered. She rediscovers what she loves about Walter - his capacity to love nature and the world around him - and so resolves to go to him and share her feelings. When he initially refuses to speak to her, she waits, patiently but stubbornly, outside his door. She realises that the situation is beyond here control, and so she simply waits. The climax of the novel occurs when Walter finally resolves to hear her out, and the result captures the importance of a changed mode of perception:

And so he stopped looking at her eyes and started looking into them, returning their look before it was too late, before this connection between life and what came after life was lost, and let her see all the vileness inside him, all the hatreds of two thousand solitary nights, while the two of them were still in touch with the void in which the sum of everything they'd ever said or done, every pain they'd inflicted, every joy they'd shared, would weigh less than the smallest feather on the wind.

"It's me," she said. "Just me."

"I know," he said, and kissed her. (559, emphasis added)

This scene brings additional nuance into the discussion that Williams and Skerrett have about Sarah's experience in the Raj Quartet. With regard to the sense of the 'body's grace', one might describe Walter and Patty as experiencing the gift of presence to each other. They experience - finally - the grace of mutual recognition and acceptance. Rather than simply looking at Patty, Richard sees more deeply into her - beyond his own subjective assumptions and needs. As was the case with Sarah in Raj Quartet, this is a momentary achievement, but it is clear that it will have lasting impact, for the difficult past that this couple has shared is not being repressed or forgotten in this moment of union, but is accepted and remains constitutive of their own individual identities. Patty feels recognised for who she really is by 
Walter, and Walter experiences, for the first time, the fullness of Patty's offer of herself to him. They are finally present to each other in a way not mediated by illusory fantasies. The previous turmoil over their conflicted desires, disappointments, jealousies and bitterness no longer hold power over their relationship. In this encounter, Walter and Patty have finally learned how to make space for each other in themselves. They have weathered the 'excruciations of finitude' (Skerrett) by achieving a more mature self-understanding, as well as an openness and genuine appreciation of each other. Rather than having their relationship shaped primarily by the fears and frustrations of the past, or by the pressures and demands of the present, they are now able to discern one another anew, and begin to discover a new identity. They are now beginning to define themselves by their future, which still lies ahead of them. As such, it can be described as an eschatological interruption of their previous selves.

In a cultural environment in which sexuality is often framed according to clear and straightforward priorities - freedom of self-expression, a natural morality based on biological anatomy, or an emphasis on the discipline of an institutional 'pastoral power' Franzen's novel illustrates the perils and inadequacies of each of these perspectives. The experiences of Walter and Patty demonstrate that the ideal of 'Using Well Thy Freedom' involves discovering a delicate balance between power and submission. The absence of power is alienating and leads to a desperate scramble for control, while absolute autonomy undermines itself. When Walter realises that 'He and his wife loved each other and brought each other daily pain' (325), the novel shows that there is no escape from this situation. Simply splitting up or merely staying together does not resolve the problem. The only possible resolution is confronting and working through the dilemma, and even then it comes only as a surprising gift. Sexuality is shown to be a key dimension to working through these dynamics, but at the same time the novel illustrates how fraught a field it is to navigate.

These observations suggest that sexual ethics is best thought of, not in terms of static categories, but in aspirational terms. While concepts like 'right-relation' and 'mutuality' can possibly serve as useful signposts, the complexity of sexual relationships cannot be reduced to these, for reasons that critics like Hauerwas and Meilaender have demonstrated. Against such critics, however, it should be recognised that the proper 'end' of sexuality can only be realised as a gift. This is undermined when one attempts to rigidly control or manipulate it. The most appropriate doctrinal location for the Christian sexual ethics is thus eschatology rather than ecclesiology or the doctrine of creation. Sexual relations do serve the wider community, but they are not simply for the community. Similarly, while one's understanding 
of sexuality is informed by one's understanding of humanity and its place in the cosmos, its end is not found merely by conforming to one's present understanding of one's nature. Rather, sexuality involves a process of discovering one's own nature in response to that of another. The fullness of one's identity, but also the fullness of one's relationship to another, are yet to be fully discovered.

This is why Jordan's suggestion that prayer is an analogy for sexuality is instructive. Prayer requires time; it cannot be reduced to mere gratification. While it involves discipline, it also seeks after something that cannot be planned for or reduced to technique. The life of prayer requires self-reflexive examination and confession, as well as open attention to the presence of another. In his book Lost Icons, Williams describes loving relationships that are able to transcend the self-absorption of psychological transference (the mistaken idea that another person possesses something that will heal or complete oneself). He suggests such successful relations move around 'the non-existent third term'. ${ }^{57}$ This sense of a 'third' element in relationships is an experience that remains elusive and superabundant. It is an experience of 'self that is present neither to my own unmediated self-awareness or selfexamination nor simply to the desiring other'. The lover's identity exceeds her or his own control, but also of the control of the beloved. Christians can understand this 'third dimension' of relationality in terms of the gift of the Spirit.

It is for this reason that descriptions of sexual relations as a sacramental means of grace (which is how some interpret William's concept of the 'body's grace') or in terms of the incarnation (following Skerrett) require further elaboration. Franzen's novel has helped illustrate that the power of erotic relationships can be distorted by the social and cultural forces that shape them. Thus, in order for sexual relations to experience that grace which Williams and Skerrett have so eloquently described, the individuals involved need to have their own agendas and desires interrupted by something beyond them. This is to say that sexual relations as such are not inherently transformative or life-giving. Missing this fact leads to the sentimentality that Hauerwas and Meilaender criticise.

The 'third dimension' of human relationships illuminates the path sought by Coakley between the dynamics of power and domination. The restlessness of the characters in Franzen's novel resonates with Augustine's observation that human hearts are restless until

\footnotetext{
${ }^{57}$ Rowan Williams, Lost Icons: Reflections on Cultural Bereavement (Harrisburg, London, New York: Morehouse, 2000), 159 (emphasis in original).
} 
they find their rest in their eschatological home. ${ }^{58}$ A successful relationship is thus one that lives out of a promise of completeness that is yet to be. It requires a trust in what is not yet fully known and remains beyond control. Patty and Walter's broken relationship is mended only after they both relinquished full control over themselves. Having had their illusions about themselves and about each other crumble, they are now in the position to have their previous ways of being together interrupted by the surprising gift of a transformative and ecstatic love. As the narrative makes clear, this breakthrough is achieved largely despite their own efforts. It is not a manufactured reconciliation, but a work of grace. It is the pneumatological and eschatological resonance of this 'third dimension' of relationality that contemporary Christian sexual ethics is often lacking.

Thus, although church teaching and saintly models may help Christians to achieve 'rightly channelled desire', ${ }^{59}$ there is no fool-proof way on this side of the eschaton to control the fluidity of human desires or avoid the inherent difficulties of navigating the architecture of choice. As Patty's and Joey's experiences illustrate, often the attempt to rigidly control desire only becomes its very stimulus. Achieving true attentiveness to the other's presence, and to oneself, takes time. This is the reason that faithfulness, understood as the giving of unlimited time to another, is so important for a moral understanding of sex. It is such faithfulness, not in the name of 'procreation' or 'natural order', but offered as part of the attempt to be attentive to the presence of the other, which stands in stark contrast to 'hooking up' culture and the frenzied consumerist consumption of contemporary capitalist social patterns.

As Walter reflects on the life of his troubled grandfather, who had immigrated to the USA from Sweden in search of boundary-less opportunity, he observes how 'The personality susceptible to the dream of limitless freedom is a personality also prone, should the dream ever sour, to misanthropy and rage' (445). Heeding this caution in the sphere is sexuality is difficult in the context of western culture's hyper-preoccupation with sex. Yet this is also a warning that helps one recognise that the promise of grace is found, not by transcending the limitations and disappointments encountered in human relationships and their inherent choices, but by working through them. This is the dynamic Paul wrestles with as he seeks to help the Corinthians understand why the freedom found in God's grace ought not to be mistaken as licence to live without regard for consequence or for the concerns of others.

\footnotetext{
${ }^{58}$ Augustine, The Confessions (New York: Penguin Books, 1961), 21 (1.1).

${ }^{59}$ Coakley, 'Rethinking the sex crises' (part 3).
} 
While all things might be lawful, not all things are beneficial (1 Cor 6.12; 10.23). This statement only seems trite and empty when one neglects the depth of the question of what is truly beneficial for one's life. Similarly, Paul's remark can only strike one as instrumentally straightforward if one ignores the contradictory and oscillating nature of human desire. Thus, contemporary Christian sexual ethics ought not to demonise individual human freedom; nor should it uncritically adopt contemporary culture's fetishised celebration of sexual liberty. Rather, the challenge confronting the churches is the question of how to help Christian individuals learn to navigate the many competing influences on their thoughts and desires, and to model a form of prayerful discernment that seeks after the mind of Christ. Deepening our understanding of the pneumatological and eschatological resonances of the 'third dimension' of relationality is a step in this direction. 